\begin{abstract}
HHS Public Access
Author manuscript

Am J Perinatol. Author manuscript; available in PMC 2018 April 01.

Published in final edited form as:

Am J Perinatol. 2017 April ; 34(5): 493-498. doi:10.1055/s-0036-1593476.

\section{Effect of body position on energy expenditure of preterm infants as determined by simultaneous direct and indirect calorimetry}

\author{
Edward F. Bell, M.D., \\ Karen J. Johnson, R.N., B.S.N., and \\ Research Coordinator, University of lowa \\ Edwin L. Dove \\ Professor of Biomedical Engineering, University of lowa
} Professor of Pediatrics, University of lowa, 200 Hawkins Drive, lowa City, IA 52242

Abstract

Indirect calorimetry is the standard method for estimating energy expenditure in clinical research. Few studies have evaluated indirect calorimetry in infants by comparing it with simultaneous direct calorimetry. Our purpose was (1) to compare the energy expenditure of preterm infants determined by these two methods, direct calorimetry and indirect calorimetry; and (2) to examine the effect of body position, supine or prone, on energy expenditure. We measured energy expenditure by simultaneous direct (heat loss by gradient-layer calorimeter corrected for heat storage) and indirect calorimetry (whole-body oxygen consumption and carbon dioxide production) in 15 growing preterm infants during two consecutive interfeeding intervals, once in the supine position and once prone. The mean energy expenditure for all measurements in both positions did not differ significantly by method used: $2.82(\mathrm{SD} 0.42) \mathrm{kcal} \cdot \mathrm{kg}^{-1} \cdot \mathrm{h}^{-1}$ by direct calorimetry and $2.78(\mathrm{SD} 0.48) \mathrm{kcal} \cdot \mathrm{kg}^{-1} \cdot \mathrm{h}^{-1}$ by indirect calorimetry. The energy expenditure was significantly lower, by $10 \%$, in the prone than in the supine position, whether examined by direct calorimetry ( 2.67 vs $2.97 \mathrm{kcal} \cdot \mathrm{kg}^{-1} \cdot \mathrm{h}^{-1}, \mathrm{P}<0.001$ ) or indirect calorimetry (2.64 vs 2.92 $\left.\mathrm{kcal} \cdot \mathrm{kg}^{-1} \cdot \mathrm{h}^{-1}, \mathrm{P}=0.017\right)$. Direct calorimetry and indirect calorimetry gave similar estimates of energy expenditure. Energy expenditure was $10 \%$ lower in the prone position than in the supine position.
\end{abstract}

\title{
Keywords
}

Energy expenditure; preterm infant; direct calorimetry; indirect calorimetry; metabolism; body position

corresponding author: edward-bell@uiowa.edu, Telephone: 319-356-4006, Fax: 319-356-4685.

The authors have no relevant conflicts of interest. 


\section{INTRODUCTION}

Mammalian energy expenditure can be measured by direct or indirect calorimetry. ${ }^{1-3}$ As energy is expended for metabolism, oxygen is consumed and carbon dioxide and heat are produced. Direct calorimetry involves measurement of the heat lost from the body by radiation, convection, and conduction, as well as calculation of the latent heat produced by evaporation of water from the skin and respiratory tract. Metabolic heat production (or energy expenditure) is derived from heat loss by correcting for heat storage in the body, which is determined by body temperature change, if any. Direct calorimetry is an accurate and sensitive method of measuring energy expenditure, but it requires enclosing the body in a special chamber. ${ }^{1-4}$ Direct calorimeters have not been widely used in human investigation because they are costly and complicated to design, build, and operate. There has been little experience with direct calorimetry in infants. ${ }^{5-11}$

Indirect calorimetry involves calculation of energy expenditure, or metabolic heat production, from the amounts of oxygen consumed and carbon dioxide produced during oxidative metabolism. It is based on the knowledge that the metabolic processes that convert food energy into heat also require oxygen and produce carbon dioxide and that these quantities - heat production, oxygen consumption, and carbon dioxide production - are related in a predictable manner. ${ }^{2,3}$ Indirect calorimetry with an open-circuit ventilated hood is a relatively simple method to use. It is particularly valuable in neonatology because it allows measurement of energy expenditure of preterm infants in their usual environment: incubator or radiant warmer. In addition, indirect calorimetry provides information about substrate utilization that is not available with direct calorimetry.

Errors may occur in estimations of energy expenditure by indirect calorimetry if energy expenditure and respiratory gas exchange are dissociated. This might happen, for example, if significant anaerobic metabolism occurs or if the body stores of oxygen or carbon dioxide are changing. During sufficiently long periods of measurement, however, indirect calorimetry is thought to provide accurate estimation of whole-body energy expenditure.

We undertook the present study to examine and compare direct and indirect calorimetry as methods of estimating energy expenditure in preterm infants. A secondary aim was to examine the influence of body position on energy expenditure as measured by direct and indirect calorimetry.

\section{METHODS}

\section{Direct calorimetry}

Direct calorimetry was performed with a calorimeter (Thermonetics Corporation, Model SEC-A-2401) built for use with infants. The calorimeter operated based on the gradientlayer principle originally described by Benzinger and Kitzinger. ${ }^{12}$ The calorimeter had a heated water jacket to allow thermal support of the infant during calorimetric measurements. The outer dimensions of the calorimeter chamber were $37.5 \times 38.5 \times 68.5 \mathrm{~cm}$. The calorimeter design was based on an animal calorimeter. A well-insulated window and a small constant-power $(1.48 \mathrm{~W})$ lamp were added to allow better visualization of the infant 
subjects. Heat loss through the walls was measured by the gradient layer. Heat loss through the window, although practically negligible, was measured with a heat-flux transducer embedded in the window. Evaporative and sensible heat losses in the ventilating air were measured by specially designed psychrometers that monitored the intake and exhaust airstreams.

Accurate use of a gradient-layer calorimeter is more difficult in infants than in adults because young infants, especially those born prematurely, require exogenous thermal support to avoid cold stress. Our calorimeter was heated to a temperature predicted to maintain normothermia and thermoneutrality by circulating heated water through copper tubes in the walls of the calorimeter. The water temperature was maintained by a circulating water bath with precisely controlled temperature. In addition to the two ventilation ports, there were small ports through which were passed feeding and intravenous catheters, cardiorespiratory monitor leads, and thermistor wires for measurement of body temperatures.

Thermistor probes (Yellow Springs Instruments, Series 400 probes) were used to continuously monitor rectal temperature and the temperatures of the abdominal, cheek, and heel skin. Each probe had been tested with a certified mercury thermometer (U.S. National Bureau of Standards) and found to agree within $0.1^{\circ} \mathrm{C}$ throughout the range from 20 to $40^{\circ} \mathrm{C}$. The rectal and skin temperatures were used to estimate mean skin temperature and to calculate heat storage, as previously described. ${ }^{13}$

The output signals from the thermoelectric sensors in the gradient layer and window and the psychrometers were recorded continuously by a data-logging system. The direct calorimeter was calibrated using an electrically heated manikin and an incandescent light bulb. ${ }^{14}$ In addition, both the direct and indirect calorimetry systems were tested simultaneously by the combustion of a known weight of ethanol. The psychrometers were tested by measurement of the evaporation of water from a vessel. The validation of the Iowa infant direct calorimeter has been described in detail by Meis et al. ${ }^{14}$

Metabolic heat production (energy expenditure) was calculated as the sum of total body heat losses, as determined by direct calorimetry, and heat storage. The body heat balance equation can be expressed as:

$$
M=E+R+C+K+S(+W)
$$

where $M$ is metabolic heat production (energy expenditure), $E$ is evaporative heat loss, $R$ is radiant heat loss, $C$ is convective heat loss, $K$ is conductive heat loss, $S$ is heat storage, ${ }^{1}$ and $W$ is external work (considered to be negligible for preterm infants). Indirect calorimetry measures $M$. Direct calorimetry measures the four components of heat loss on the right side of the equation and, by adding heat storage, produces a second estimation of metabolic heat production. Body heat storage $(S)$ was calculated from the change in body temperatures, assuming the specific heat of the infant's body to be $0.84 \mathrm{kcal} \cdot \mathrm{kg}^{-1} \cdot{ }^{\circ} \mathrm{C}^{-1}$, as reported by Ryser and Jéquier ${ }^{8}$ : 


$$
S=0.84 \mathrm{kcal} \cdot \mathrm{kg}^{-1} \cdot{ }^{\circ} \mathrm{C}^{-1} \cdot\left(0.6 \Delta \mathrm{T}_{\mathrm{r}}+0.4 \Delta \hat{\mathrm{a}} \hat{\mathrm{C}} \ddot{y}_{\mathrm{s}}\right) / \Delta \mathrm{t}
$$

where $\Delta \mathrm{T}_{\mathrm{r}}$ is the change in rectal temperature, $\Delta_{\mathrm{S}}$ is the change in mean skin temperature, and $\Delta \mathrm{t}$ is the duration of the measurement period (in hours).

\section{Indirect calorimetry}

Attachment of the ventilation tubes to our previously described indirect calorimetry system (Fig. 1) allowed measurement of whole-body oxygen consumption and carbon dioxide production, from which energy expenditure could be calculated as previously described. ${ }^{13}$ Indirect calorimetry was performed using a flow-through system to measure whole-body oxygen and carbon dioxide exchange. Because the infants were enclosed in the direct calorimeter chamber, a head hood was not required for the collection of expired gas. Instead, oxygen and carbon dioxide concentrations were measured in the intake and exhaust sides of the ventilating circuit for the direct calorimeter. Oxygen concentration was measured with a paramagnetic analyzer (Servomex OA540), and carbon dioxide concentration was measured with an infrared analyzer (Beckman LB2). The oxygen and carbon dioxide analyzers were calibrated with pure nitrogen and a gas mixture of known composition, certified to be accurate to within 1 part in 10,000. The composition of the calibration gas was verified through analysis by the Haldane procedure. ${ }^{15,16} \mathrm{Gas}$ flow was controlled at $31 \cdot \mathrm{min}^{-1} \cdot \mathrm{kg}^{-1}$ and measured with an electronic flow controller and hot-wire flowmeter (Matheson 8240) after passing through a drying column. The flowmeter automatically corrects volumes to standard temperature and pressure. The flowmeter was calibrated by the timed filling of a 120 -liter spirometer. Flowmeter results were expressed as STPD volumes. Output signals from the gas analyzers and flowmeter were continuously recorded and averaged by an electronic data logging system. Oxygen consumption and carbon dioxide production were calculated from the gas concentrations and flow. Metabolic heat production (energy expenditure) was calculated from oxygen consumption and carbon dioxide production. ${ }^{13}$ The indirect calorimetry system was validated by calculating the simulated gas exchange resulting from the addition of pure nitrogen ${ }^{17}$ or carbon dioxide at known rates. The error of the indirect calorimetry system is less than $5 \% .^{18}$

\section{Combined direct and indirect calorimetry system}

The combined direct and indirect calorimetry system (Fig. 1) was tested by measurement of the oxygen consumed and the carbon dioxide, heat, and water produced during the combustion of ethanol, as previously described. ${ }^{14}$

\section{Infant studies}

We studied 15 healthy growing preterm infants ( 9 males) with mean birth weight $1.32 \mathrm{~kg}$ (range $0.91-1.81 \mathrm{~kg}$ ) and mean gestational age 29.3 weeks (range 25-33 weeks). One infant was small for gestational age, and one was large for gestational age; the other $13 \mathrm{had}$ appropriate birth weights for their gestational ages. Energy expenditure was determined by simultaneous direct and indirect calorimetry during two consecutive interfeeding intervals of 3 hours each, once in the supine position and once prone, with the order determined 
randomly. Immediately after completion of a gavage feeding, the calorimeter was closed, and measurements were begun 60 minutes later to allow time for thermal equilibration. Measurements were continued for 90 to 120 minutes, until the next feeding. After the second feeding the infant was placed in the other body position, and the measurements were repeated. The infants were naked except for a plastic-coated diaper, which was changed before each measurement period. For one infant, the prone measurements could not be completed.

The direct and indirect calorimetric determinations of energy expenditure were compared. The sample size of 15 infants provided $95 \%$ power (with 2-tailed a 0.05 ) to detect a difference in energy expenditure of $4.9 \mathrm{kcal} \cdot \mathrm{kg}^{-1} \cdot \mathrm{d}^{-1}(7.8 \%)$ between direct and indirect calorimetry, the difference reported by Sauer et al., ${ }^{10}$ with standard deviation $\sigma$ equal to the difference, $\delta$, between means. The impact of body position on energy expenditure was examined by comparing energy expenditure in the two positions, prone and supine; this comparison was made separately using the direct and indirect calorimetric determinations of energy expenditure. All statistical analyses were performed using the $t$ test for paired observations.

The study was approved by the University of Iowa biomedical institutional review board, and written informed consent was obtained from one or both parents of each subject.

\section{RESULTS}

At the time of study, the mean age of the infants was 23.6 days (range 6-51 days) and the mean body weight was $1.55 \mathrm{~kg}$ (range $1.21-1.74 \mathrm{~kg}$ ).

The mean energy expenditure for all infants was $2.82(\mathrm{SD} 0.42) \mathrm{kcal} \cdot \mathrm{kg}^{-1} \cdot \mathrm{h}^{-1}$ by direct calorimetry and $2.78(\mathrm{SD} 0.48) \mathrm{kcal} \cdot \mathrm{kg}^{-1} \cdot \mathrm{h}^{-1}$ by indirect calorimetry (Table 1 ), a difference of $1.7 \%$; these values were not significantly different $(\mathrm{P}=0.570)$. The difference exceeded $10 \%$ of the mean of the two measurements in 10 of 29 measurement periods; in 5 of these 10 , the estimate by direct calorimetry was higher (Table 1).

The energy expenditure was $10 \%$ lower in the prone than in the supine position, whether examined by direct or indirect calorimetry. With direct calorimetry, mean energy expenditure was 2.97 (SD 0.40) $\mathrm{kcal} \cdot \mathrm{kg}^{-1} \cdot \mathrm{h}^{-1}$ while supine and 2.67 (SD 0.40) $\mathrm{kcal} \cdot \mathrm{kg}^{-1} \cdot \mathrm{h}^{-1}$ while prone $(\mathrm{P}<0.001)$. With indirect calorimetry, mean energy expenditure was 2.92 (SD 0.48) $\mathrm{kcal} \cdot \mathrm{kg}^{-1} \cdot \mathrm{h}^{-1}$ while supine and $2.64(\mathrm{SD} 0.46) \mathrm{kcal} \cdot \mathrm{kg}^{-1} \cdot \mathrm{h}^{-1}$ while prone $(\mathrm{P}=0.017)$.

\section{DISCUSSION}

Although most adult human studies have shown close agreement between simultaneous direct and indirect calorimetry, ${ }^{19,20}$ others have shown differences in certain situations. Pullar and coworkers ${ }^{21}$ and Pittet et al. ${ }^{22}$ showed discrepancies in adults between heat production by indirect calorimetry and heat losses by direct calorimetry, but the differences were in the direction that would be accounted for by heat storage. 
Webb and coworkers found that adult subjects with normal activity and diet showed close agreement between heat production by indirect calorimetry and heat loss by direct calorimetry, as expected in a setting where heat storage was negligible, as was documented in their study. ${ }^{23}$ However, in subjects who were underfed and exercised vigorously, the heat production was larger than heat loss by direct calorimetry, by $8 \%$ to $23 \%$. This effect could not be explained by heat storage, and the authors could find no adequate explanation for this excess of heat production over heat loss.

To our knowledge, there have been only four previous studies comparing results by simultaneous direct and indirect calorimetry in infants (Table 2). $5,7,9,10$

Howland measured the heat production of two infants, ages 3 and 7 months, by simultaneous direct and indirect calorimetry and found that the estimates of heat production by these methods differed by $3 \%$ or less in all of 13 measurements. ${ }^{5}$

Day et al. reported 50 paired measurements of heat production by concurrent direct and indirect calorimetry in 25 large, healthy male preterm infants. ${ }^{7}$ The overall means for direct and indirect calorimetry agreed closely, $70.4 \mathrm{vs} 70.9 \mathrm{kcal} \cdot \mathrm{kg}^{-1} \cdot \mathrm{d}^{-1}$; however, in 17 of 50 cases, the results by direct and indirect calorimetry differed by $10 \%$ or more. The authors concluded that the experimental error was "small enough to permit conclusions about the group of infants as a whole, but ... too large to warrant speculation about any one infant."

Salomon et al. performed simultaneous direct and indirect calorimetry in 29 term infants. ${ }^{9}$ The relation between total heat loss by direct calorimetry and metabolic heat production by indirect calorimetry varied, and these were not systematically compared, but the results by indirect calorimetry were generally higher.

Sauer and coworkers performed 54 paired measurements of total metabolic heat production by indirect calorimetry and heat loss by direct calorimetry in 14 growing preterm infants between 8 and 58 days of age. ${ }^{10}$ The heat loss by direct calorimetry was lower than heat production by indirect calorimetry in 53 cases out of 54; the mean heat loss by direct calorimetry was $21.8 \mathrm{~kJ} \cdot \mathrm{kg}^{-1} \cdot \mathrm{d}^{-1}\left(4.9 \mathrm{kcal} \cdot \mathrm{kg}^{-1} \cdot \mathrm{d}^{-1}\right)$ lower than the mean heat production (metabolic rate) by indirect calorimetry, a difference of $7.8 \%$. This difference was statistically significant $(\mathrm{P}<0.001)$. The authors attributed this difference to a portion of the energy expended for synthesis of new tissues - the portion that is consumed in the synthetic process but not given off as heat.

The results of our comparison of direct and indirect calorimetry were similar to those of Day et $\mathrm{al}^{7}$; there was no difference overall between direct and indirect calorimetric determinations of energy expenditure, although differences were found in individual patients. Day and his coworkers found a difference of $10 \%$ or more between direct and indirect calorimetry for 17 of 50 studies (34\%).

Our results comparing direct and indirect calorimetry are consistent with those of Howland ${ }^{5}$ and Day et al. ${ }^{7}$ but not with Sauer et al. ${ }^{10}$ We did not find the systematic difference between direct and indirect calorimetric results reported by Sauer and his coworkers. Our study was powered at the $95 \%$ level to find a difference of the size reported by Sauer et al.; however, it 
is still possible that we missed such a difference with our sample of 15 infants because our patient-to-patient variance in the difference between direct and indirect calorimetry was larger than that seen in the patients of Sauer et al. It is also possible that a systematic error in direct or indirect calorimetry in the work of Sauer et al or in our own studies accounted for our discordant findings. The difference observed by Sauer et al. could have resulted, for example, from failure to account for heat storage if the infants' body temperatures were rising in the calorimeter. In our own studies, we could have missed detecting a difference between direct and indirect calorimetry by excluding the first hour after feeding. We waited 1 hour to allow for steady-state measurements in the calorimeter; however, if there is a difference between direct and indirect calorimetry that depends on the time from feeding, we might have missed the period of greatest difference by waiting 1 hour after feeding to begin recording our measurements. Our study shows that for infants, in whom external work is negligible, indirect calorimetry can provide accurate estimation of total body heat losses as measured by direct calorimetry, provided heat storage is considered.

Our finding of lower energy expenditure with prone positioning compared with supine agrees with some ${ }^{24,25}$ but not all ${ }^{26}$ earlier reports. The lower energy expenditure in the prone position has several possible explanations. First, in the prone position, infants tend to hold their extremities more flexed, reducing the area of surface exposed for heat loss. Second, infants are less active and spend more time sleeping when in the prone position. ${ }^{24,27}$ Third, the work of breathing is less in the prone position, ${ }^{28}$ because gravity aids lung expansion in this position. Moreover, thoracoabdominal respiratory asynchrony is reduced in the prone position, ${ }^{29}$ and oxygenation is improved, ${ }^{28,30}$ presumably due to improved ventilationperfusion matching. ${ }^{29}$

\section{CONCLUSIONS}

Our results did not demonstrate a systematic difference in the measurement of energy expenditure (metabolic heat production) by simultaneous direct and indirect calorimetry in preterm infants. Direct and indirect calorimetry were concordant in demonstrating a $10 \%$ reduction in energy expenditure when infants are nursed in the prone position rather than supine. By demonstrating equivalence to direct calorimetry, our results support the continued use of indirect calorimetry, a more practical method of assessing energy expenditure.

\section{Acknowledgments}

This research was supported by grants R01 HD16974, P01 HD07578, and M01 RR00059 from the National Institutes of Health. The authors acknowledge the contributions of Steven J. Meis, Jeffrey S. McKinney, MargitAndrea Glatzl-Hawlik, and Charlotte M. Thompson, all of whom helped with some aspect of this study. We thank the patients who participated and their parents, who granted consent for their participation.

\section{References}

1. Webb, P. Human Calorimeters. New York: Praeger; 1985. p. 1-10.

2. McLean, JA., Tobin, G. Animal and Human Calorimetry. Cambridge, UK: Cambridge University Press; 1987. p. 120-183.

3. Jéquier E, Acheson K, Schutz Y. Assessment of energy expenditure and fuel utilization in man. Ann Rev Nutr. 1987; 7:187-208. [PubMed: 3300732] 
4. Schutz Y. The basis of direct and indirect calorimetry and their potentials. Diabetes Metab Rev. 1995; 11:383-408. [PubMed: 8718497]

5. Howland J. Direct calorimetry of infants, with a comparison of the results obtained by this and other methods. Trans 15th Int Congr Hyg Demog. 1912; 2:438-451.

6. Day R, Hardy JD. Respiratory metabolism in infancy and in childhood. XXVI. A calorimeter for measuring the heat loss of premature infants. Am J Dis Child. 1942; 63:1086-1095.

7. Day R, Curtis J, Kelly M. Respiratory metabolism in infancy and in childhood. XXVII. Regulation of body temperature of premature infants. Am J Dis Child. 1943; 65:376-398.

8. Ryser G, Jéquier E. Study by direct calorimetry of thermal balance on the first day of life. Eur J Clin Invest. 1972; 2:176-187. [PubMed: 5038807]

9. Salomon JW, Swyer PR, Jéquier E. Thermic effects of glucose, amino acid and lipid in the term newborn. Biol Neonate. 1979; 35:8-16. [PubMed: 420889]

10. Sauer PJJ, Dane HJ, Visser HKA. Longitudinal studies on metabolic rate, heat loss, and energy cost of growth in low birth weight infants. Pediatr Res. 1984; 18:254-259. [PubMed: 6728558]

11. Rao M, Koenig E, Li S, et al. Direct calorimetry for the measurement of heat release in preterm infants: methods and applications. J Perinatol. 1995; 15:375-381. [PubMed: 8576750]

12. Benzinger TH, Kitzinger C. Direct calorimetry by means of the gradient principle. Rev Sci Instrum. 1949; 20:849-860. [PubMed: 15402229]

13. Bell EF, Rios GR. A double-walled incubator alters the partition of body heat loss of premature infants. Pediatr Res. 1983; 17:135-140. [PubMed: 6402753]

14. Meis SJ, Dove EL, Bell EF, et al. A gradient-layer calorimeter for measurement of energy expenditure of infants. Am J Physiol. 1994; 266:R1052-R1060. [PubMed: 8160854]

15. Haldane J. A new form of apparatus for measuring the respiratory exchange of animals. $J$ Physiol. $1892 ; 13: 419-430$.

16. Consolazio, CF., Johnson, RE., Pecora, LJ. Physiological Measurements of Metabolic Functions in Man. New York: McGraw-Hill; 1963. p. 61-71.

17. Kappagoda CT, Linden RJ. A critical assessment of an open circuit technique for measuring oxygen consumption. Cardiovasc Res. 1972; 6:589-597. [PubMed: 5076283]

18. Bell EF, Rios GR, Wilmoth PK. Estimation of 24-hour energy expenditure from shorter measurement periods in premature infants. Pediatr Res. 1986; 20:646-649. [PubMed: 3725462]

19. Dauncey MJ. Metabolic effects of altering the $24 \mathrm{~h}$ energy intake in man, using direct and indirect calorimetry. Br J Nutr. 1980; 43:257-269. [PubMed: 7378336]

20. Seale JL, Rumpler WV, Conway JM, Miles CW. Comparison of doubly labeled water, intakebalance, and direct- and indirect-calorimetry methods for measuring energy expenditure in adult men. Am J Clin Nutr. 1990; 52:66-71. [PubMed: 2193502]

21. Pullar, JD., Brockway, JM., McDonald, JD. A comparison of direct and indirect calorimetry. In: Blaxter, KL.Kielanowski, J., Thorbek, G., editors. Energy Metabolism of Farm Animals. Newcastle-Upon-Tyne: Oriel Press; 1969. p. 415-421.

22. Pittet P, Gygax PH, Jéquier E. Thermic effect of glucose and amino acids in man studies by direct and indirect calorimetry. Br J Nutr. 1974; 31:343-349. [PubMed: 4835787]

23. Webb P, Annis JF, Troutman SJ Jr. Energy balance in man measured by direct and indirect calorimetry. Am J Clin Nutr. 1980; 33:1287-1298. [PubMed: 7386416]

24. Masterson J, Zucker C, Schulze K. Prone and supine positioning effects on energy expenditure and behavior of low birth weight neonates. Pediatrics. 1987; 80:689-692. [PubMed: 3670970]

25. Ammari A, Schulze KF, Ohira-Kist K, et al. Effects of body position on thermal, cardiorespiratory and metabolic activity in low birth weight infants. Early Hum Dev. 2009; 85:497-501. [PubMed: 19419824]

26. Dollberg S, Yacov G, Mimouni FB, Barak M. The effect of positioning on energy expenditure in preterm infants: a feasibility study. Am J Perinatol. 2004; 21:391-394. [PubMed: 15476129]

27. Chang YJ, Anderson GC, Dowling D, Lin CH. Decreased activity and oxygen desaturation in prone ventilated preterm infants during the first postnatal week. Heart Lung. 2002; 31:34-42. [PubMed: 11805748] 
28. Mizuno K, Aizawa M. Effects of body position on blood gases and lung mechanics of infants with chronic lung disease during tube feeding. Pediatr Int. 1999; 41:609-614. [PubMed: 10618878]

29. Martin RJ, Herrell N, Rubin D, Fanaroff A. Effect of supine and prone positions on arterial oxygen tension in the preterm infant. Pediatrics. 1979; 63:528-531. [PubMed: 440861]

30. McEvoy C, Mendoza ME, Bowling S, Hewlett V, Sardesai S, Durand M. Prone positioning decreases episodes of hypoxemia in extremely low birth weight infants (1000 grams or less) with chronic lung disease. J Pediatr. 1997; 130:305-309. [PubMed: 9042137] 


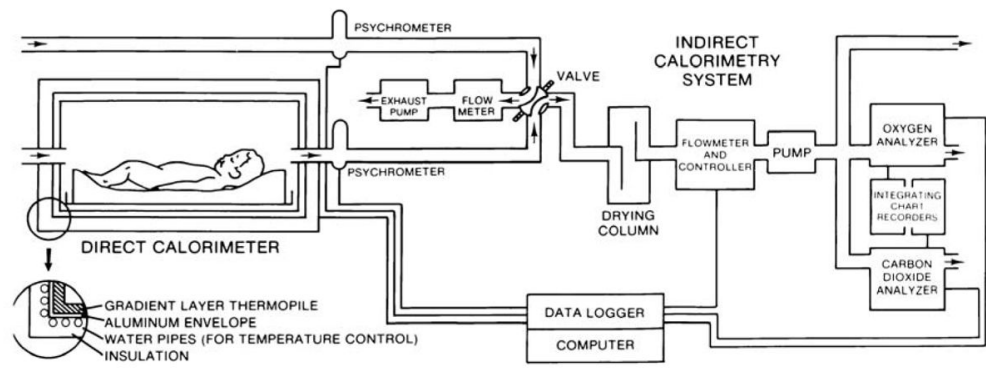

Fig. 1.

System for simultaneous direct and indirect calorimetry. 


\section{Table 1}

Energy expenditure in supine and prone positions determined by simultaneous direct and indirect calorimetry in preterm infants

\begin{tabular}{|c|c|c|c|c|}
\hline \multirow[b]{2}{*}{ Patient } & \multirow[b]{2}{*}{ Position } & \multicolumn{3}{|c|}{ Energy expenditure $\left(\mathrm{kcal} \cdot \mathrm{kg}^{-1} \cdot \mathbf{h}^{-1}\right)$} \\
\hline & & Direct & Indirect & Difference \\
\hline \multirow[t]{2}{*}{1} & Supine & 2.70 & 2.30 & 0.40 \\
\hline & Prone & 2.39 & 2.37 & 0.02 \\
\hline \multirow[t]{2}{*}{2} & Supine & 3.13 & 3.22 & -0.09 \\
\hline & Prone & 3.01 & 3.14 & -0.13 \\
\hline \multirow[t]{2}{*}{3} & Supine & 2.51 & 2.63 & -0.12 \\
\hline & Prone & - & - & - \\
\hline \multirow[t]{2}{*}{4} & Supine & 2.53 & 1.86 & 0.67 \\
\hline & Prone & 1.91 & 2.15 & -0.24 \\
\hline \multirow[t]{2}{*}{5} & Supine & 3.01 & 3.50 & -0.49 \\
\hline & Prone & 2.59 & 3.26 & -0.67 \\
\hline \multirow[t]{2}{*}{6} & Supine & 2.46 & 3.16 & -0.70 \\
\hline & Prone & 2.12 & 1.99 & 0.13 \\
\hline \multirow[t]{2}{*}{7} & Supine & 3.68 & 3.39 & 0.29 \\
\hline & Prone & 2.80 & 3.15 & -0.35 \\
\hline \multirow[t]{2}{*}{8} & Supine & 3.59 & 3.38 & 0.21 \\
\hline & Prone & 2.90 & 2.68 & 0.22 \\
\hline \multirow[t]{2}{*}{9} & Supine & 2.84 & 3.07 & -0.23 \\
\hline & Prone & 2.79 & 2.90 & -0.11 \\
\hline \multirow[t]{2}{*}{10} & Supine & 3.02 & 3.13 & -0.11 \\
\hline & Prone & 2.88 & 2.86 & 0.02 \\
\hline \multirow[t]{2}{*}{11} & Supine & 2.86 & 2.97 & -0.11 \\
\hline & Prone & 2.59 & 2.70 & -0.11 \\
\hline \multirow[t]{2}{*}{12} & Supine & 2.46 & 2.22 & 0.24 \\
\hline & Prone & 2.22 & 2.21 & 0.01 \\
\hline \multirow[t]{2}{*}{13} & Supine & 3.46 & 3.24 & 0.22 \\
\hline & Prone & 3.30 & 3.18 & 0.12 \\
\hline \multirow[t]{2}{*}{14} & Supine & 3.05 & 2.75 & 0.30 \\
\hline & Prone & 2.70 & 2.46 & 0.24 \\
\hline \multirow[t]{2}{*}{15} & Supine & 3.21 & 2.93 & 0.28 \\
\hline & Prone & 3.21 & 1.91 & 1.30 \\
\hline
\end{tabular}

Am J Perinatol. Author manuscript; available in PMC 2018 April 01. 


\begin{tabular}{|c|c|c|c|c|}
\hline \multirow[b]{2}{*}{ Patient } & \multirow[b]{2}{*}{ Position } & \multicolumn{3}{|c|}{ Energy expenditure $\left(\mathrm{kcal} \cdot \mathrm{kg}^{-1} \cdot \mathrm{h}^{-1}\right)$} \\
\hline & & Direct & Indirect & Difference \\
\hline \multirow[t]{2}{*}{ Mean (SD) } & Supine & $2.97(0.40)^{*}$ & $2.92(0.48)^{\dagger}$ & $0.05(0.36)$ \\
\hline & Prone & $2.67(0.40)^{*}$ & $2.64(0.46)^{\dagger}$ & $0.03(0.44)$ \\
\hline Mean (SD) & Overall & $2.82(0.42)^{t}$ & $2.78(0.48)^{t}$ & $0.04(0.39)$ \\
\hline \multicolumn{5}{|c|}{${ }^{*}<0.001$, supine vs prone, direct calorimetry } \\
\hline \multicolumn{5}{|c|}{${ }_{\mathrm{P}=0.017}^{\prime}$, supine vs prone, indirect calorimetry } \\
\hline
\end{tabular}


Bell et al.

Page 13

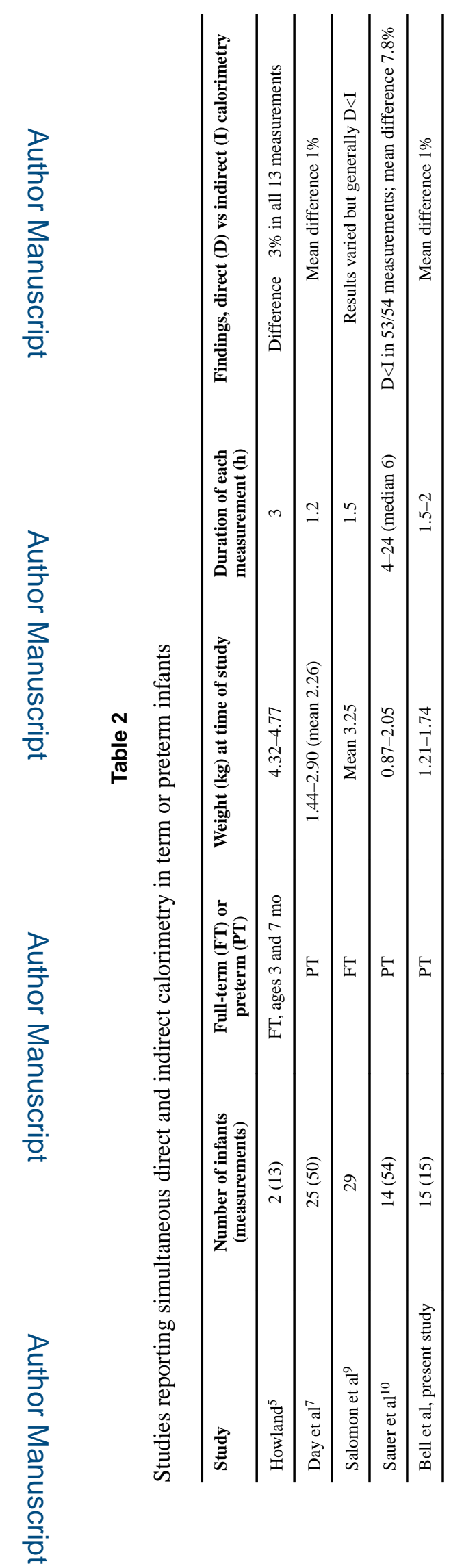

Am J Perinatol. Author manuscript; available in PMC 2018 April 01. 